\title{
SISTEM PATROLI SECURITY PADA PT SINAR SOSRO
}

\author{
Kiky Andriani Putri, Ali Mahmudi, Nurlaily Vendyansyah \\ Program Studi Teknik Informatika S1, Fakultas Teknologi Industri \\ Institut Teknologi Nasional Malang, Jalan Raya Karanglo km 2 Malang, Indonesia \\ 1618111@scholar.itn.ac.id
}

\begin{abstract}
ABSTRAK
Untuk menjaga keamanan dilingkungan perusahaan, PT SINAR SOSRO menggunakan petugas security untuk membantu pengawasan. Sistem keamanan yang biasanya dilakukan oleh petugas security adalah dengan cara melakukan patroli dengan menggunakan suatu alat manual yang disebut "Amano". Alat ini berukuran $20 \mathrm{~cm}$ $\mathrm{x} 20 \mathrm{~cm}$ yang akan dibawa oleh setiap petugas security berkeliling melakukan patroli dengan kunci disetiap area nya berbeda-beda. Untuk cara kerja amano sendiri yaitu amano akan dibawa berkeliling untuk patroli dengan cara diselempangkan di bahu, kemudian amano akan mengambil data disetiap titik-titik patroli yang dimana pada setiap titik petugas security akan memasang kunci yang berbeda untuk mengambil datanya. Data yang diambil yaitu berupa data tempat area melakukan patroli. Setelah dilakukan pengecekan secara rinci

Dibuatlah suatu system untuk melakukan kegiatan patroli security yang akan digunakan oleh petugas security dalam melakukan kegiatan patroli yang dibangun berbasis mobile. System patroli security akan dioperasikan oleh dua pengguna yaitu petugas security yang akan menginputkan data-data yang wajib diisikan pada saat melakukan kegiatan patroli. Untuk pengguna kedua merupakan admin atau dalam perusahaan disebut koordinator lapangan. Sistem patroli ini dilakukan oleh security secara bergantian sesua dengan shift (jam kerja) masing-masing, dan petugas security juga memiliki username dan password masing-masing untuk dapat mengakses aplikasi atau system ini. Pada system ini petugas security akan melakukan pelaporan dan akan di validasi oleh admin pengelola.

Oleh karena itu aplikasi yang berbasis website untuk mengoptimalkan kinerja petugas security yang mengkonversikan sistem patroli yang masih manual menjadi digital. Aplikasi ini juga membantu pengawasan $C C T V$ disetiap area patroli karna dengan luas area yang dimiliki tidak memungkin untuk perusahaan memasang $C C T V$ pada setiap titik patroli dan tentunya lebih meminimalisir pengeluran yang dikeluarkan oleh perusahaan. Dalam pengawasan ini sistem akan bekerja secara online sehingga dalam semua area patroli security akan mengambil data waktu dan tempat dimana petugas security tersebut melakukan patroli menggunakan waktu server sehingga seakan memaksa petugas security untuk patroli dan melakukan tanggung jawabnya
\end{abstract}

Kata Kunci : patroli, security,pengawasan, sinar sosro, system

\section{PENDAHULUAN}

PT SINAR SOSRO merupakan perusahaan yang bergerak di bidang minuman, PT SINAR SOSRO memiliki dua cabang perusahaan yang berada di Wilayah Mojokerto dan Pandaan. Untuk menjaga keamanan dilingkungan perusahaan, PT SINAR SOSRO menggunakan petugas security untuk membantu pengawasan. System keamanan yang biasanya dilakukan oleh petugas security adalah dengan cara melakukan patrol dengan menggunakan suatu alat manual yang disebut "Amano". Alat ini berukuran $20 \mathrm{~cm} \times 20 \mathrm{~cm}$ yang akan dibawa oleh setiap petugas security berkeliling melakukan patroli dengan kunci disetiap area nya berbeda-beda. Untuk cara kerja amano sendiri yaitu amano akan dibawa berkeliling untuk patroli dengan cara diselempangkan di bahu, kemudian amano akan mengambil data disetiap titik-titik patroli yang dimana pada setiap titik petugas security akan memasang kunci yang berbeda untuk mengambil datanya. Data yang diambil yaitu berupa data tempat area melakukan patroli. Setelah dilakukan pengecekan secara rinci
Alat tersebut kurang efektif dalam membantu meningkatkan kinerja petugas security di perusahaan, dikarenakan alat tersebut juga tidak ada system pelaporan. Penulis berkesempatan membuat suatu aplikasi berbasis website yang kemudian di aplikasikan pada smartphone untuk mengoptimalkan kinerja petugas security yang berada di PT SINAR SOSRO.

Oleh karena itu aplikasi yang berbasis website untuk mengoptimalkan kinerja petugas security yang mengkonversikan sistem patroli yang masih manual menjadi digital. Aplikasi ini juga membantu pengawasan $C C T V$ disetiap area patroli karna dengan luas area yang dimiliki tidak memungkin untuk perusahaan memasang $C C T V$ pada setiap titik patroli dan tentunya lebih meminimalisir pengeluran yang dikeluarkan oleh perusahaan. Dalam pengawasan ini sistem akan bekerja secara online sehingga dalam semua area patroli security akan mengambil data waktu dan tempat dimana petugas security tersebut melakukan patroli menggunakan waktu server sehingga seakan memaksa petugas security untuk patroli dan melakukan tanggung jawabnya. Aplikasi 
ini juga akan membantu kegiatan monitoring kinerja petugas security secara online di 2 Cabang yang berbeda yaitu di Mojokerto dan Pandaan.

\section{TINJAUAN PUSTAKA}

Penelitian dengan judul "PERANCANGAN APLIKASI PATROLI KEAMANAN DAN KESELAMATAN KAMPUS" menjelaskan tentang eamanan lingkungan merupakan kondisi utama untuk menciptakan suasana kerja yang kondusif dan sebagai upaya untuk menjaga segala aset atau sumber daya dalam suatu organisasi. Semakin tinggi tingkat keamanan suatu lingkungan akan semakin rendah risiko kerugian akibat kehilangan aset atau bahaya yang mengancam personil. Petugas kemanan dalam suatu lingkungan kerja menjadi salah satu tumpuan untuk melaksanakan fungsi-fungsi pengamanan dan penyelamatan. Proses monitoring keamanan lingkungan kampus dilakukan secara rutin dengan jadwal patroli yang terjadwal dan umumnya memiliki klasterisasi area pengamanan agar optimal. SIGAP ITS merupakan aplikasi bergerak yang dirancang untuk memastikan personil yang bertugas mengikuti jadwal optimal patroli dan memastikan personil telah mengunjungi gedung yang harus diawasi. Imlementasi SIGAP ITS menjadi solusi pemantauan sistem keamanan yang realtime dan dinamis.

(Rahman, 2018 )

Penelitian dengan judul "EFEKTIFITAS PELAKSANAAN PATROLI TERPADU DALAM UPAYA MENEKAN TINGKAT KRIMINALITAS

(PADA POLRES BUNGO)" menjelaskan tentang peran dan tugas pokok Polri adalah bertujuan untuk mewujudkan keamanan dalam negeri yang meliputi terpeliharanya keamanan dan ketertiban masyarakat, tertib dan tegaknya hukum, terselenggaranya perlindungan, pengayoman, dan pelayanan kepada masyarakat dan menjunjung tinggi hak asasi manusia sebagaimana Undang-undang Nomor 2 Tahun 2002 tentang Kepolisian RI. Berkaitan dengan hal tersebut, Polres Bungo melaksanakan peran dan fungsi Polri tersebut, salah satu programnya adalah dalam bentuk Patroli Terpadu yang bertujuan untuk menjaga keamanan dan ketertiban masyarakat. Penelitian ini bertujuan untuk untuk mengetahui pelaksanaan patroli terpadu, untuk mengetahui hambatan dalam pelaksanaan patroli terpadu, untuk mengetahui upaya yang dilakukan dalam mengatasi hambatan tersebut diatas. Metode yang digunakan dalam penelitian ini adalah metode deskriptif dengan analisa kualitatif, Populasi dalam penelitian ini adalah Kepala dan seluruh anggota Polres Bungo serta masyarakat Kabupaten Bungo. Sedangkan sampel adalah adalah sebagian dari populasi yang akan kita selidiki. Dalam penelitian ini, sampel yang diambil dan ditetapkan berjumlah 14 orang. Hasil Penelitian menunjukan Bahwa pelaksanaan patroli terpadu Polres Bungo telah berjalan dalam rangka melaksanakan peran dan tugas keamanan masyaraka, namun pelaksanaan patroli terpadu masih mengalami kendala atau belum optimal.

Hambatanhambatan yang dihadapi oleh Polres Bungo dalam pelaksanaan patroli terpadu adalah dikarenakan keterbatasan Sumber Daya Manusia dan kurangnya sarana dan prasarana. Upaya-upaya yang dilakukan oleh Polres Bungo dalam mengatasi hambatan yang dihadapi dalam pelaksanaan patroli adalah melalui program pembinaan dan pendidikan anggota Polres Bungo dan program rekrutmen anggota polisi. Disamping itu perlu dilakukan pendekatan secara arif, melakukan penyuluhan dan sosialisasi kepada masyarakat.

(Burhanuddin, 2017)

\subsection{Data}

Data bisa juga didefinisikan sekumpulan informasi atau nilai yang diperoleh dari pengamatan (observasi) suatu obyek, data dapat berupa angka dan dapat pula merupakan lambing atau sifat. Beberapa macam data antara lain : data populasi dan sampel, data observasi, data primer, dan data sekunder. (Webster New World Dictionary 2010)

\subsection{HTML}

Sistem operasi yang berbasis Linux untuk telepon seluler seperti telepon pintar dan komputer tablet. Android menyediakan platform terbuka bagi para pengembang untuk menciptakan aplikasi mereka sendiri untuk digunakan oleh bermacam peranti bergerak. Awalnya Google Inc. membeli Android Inc pendatang baru yang membuat peranti lunak untuk ponsel. Kemudian untuk mengembangkan Android, dibentuklah Open Handset Alliance, konsorsium dari 34 perusahaan peranti keras, peranti lunak, dan telekomunikasi, termasuk Google, HTC, Intel, Motorola, Qualcomm, T- Mobile, dan Nvidia. ( brainly, 2006 )

\subsection{2.3 PHP}

PHP adalah bahasa pemrograman script serverside yang didesain untuk pengembangan web. Selain itu, PHP juga bisa digunakan sebagai bahasa pemrograman umum. PHP di kembangkan pada tahun 1995 oleh Rasmus Lerdorf, dan sekarang dikelola oleh The PHP Group. Situs resmi PHP beralamat di http://www.php.net.(Kusuma Nyoman, 2008 )

\subsection{MySQL}

MySQL adalah sistem manajemen database yang digunakan untuk menyimpan data dalam tabel terpisah dan menempatkan semua data dalam satu gudang besar. Struktur database disusun dalam file fisik dioptimalkan untuk kecepatan. Model logis, dengan benda-benda seperti database, tabel, baris, dan kolom, menawarkan lingkungan pemrograman yang Fleksibel.( Kusuma Nyoman, 2008 ) 


\subsection{Hosting}

Layanan berbasis internet yang menyediakan sumber daya atau resource untuk disewakan sebagai tempat menyimpan data atau tempat menjalankan aplikasi atau website ditempat terpusat yang disebut dengan server sehingga memungkinkan organisasi atau individu menempatkan informasi di internet berupa HTTP, FTP, EMAIL, atau DNS. Dari pengertian hosting diatas dapat disimpulkan bahwa hosting adalah ibarat sebuah rumah yang disewakan dengan ukuran tertentu dan setiap bangunan rumah pasti memiliki ukuran yang berbeda. ( Sevima, 2015 )

\subsection{Android}

Telepon genggam yang mempunyai kemampuan tingkat tinggi. Belum ada standar pabrik yang menentukan arti Smartphone. Bagi beberapa orang, smartphone merupakan telepon yang bekerja menggunakan seluruh perangkat lunak sistem operasi yang menyediakan hubungan standar dan mendasar bagi pengembang aplikasi. ( Teguh Affrianto, 2011 )

\subsection{Patroli}

Patroli merupakan salah satu kegiatan kepolisian yang dilakukan oleh dua orang anggota polri atau lebih sebagai usaha mencegah bertemunya niat dan kesempatan, dengan jalan mendatangi, menjelajahi, mengamati atau memperhatikan situasi dan kondisi yang diperkirakan akan menimbulkan segala bentuk pelanggaran.( Marselina,2017 )

\subsection{Security}

Security ini merupakan dokumen yang harus dimiliki perusahaan untuk mengamankan aset pentingnya, juga menghindari adanya insiden atau tuntutan hukum jika organisasi tersebut lalai dalam melakukan pengelolaan internal pada aset informasinya. ( Peter Salim, 2002 )

\section{ANALISI DAN PERANCANGAN}

\subsection{Analisis Kebutuhan}

Aplikasi mobile yang digunakan untuk melakukan pencatatan secara online dan real time yang menggunakan data GPS sebagai acuan dalam melakukan inspeksi / patroli sehingga akan diketahui pencatatan tersebut berasal dari area yang bersangkutan. Aplikasi ini dapat dijalankan baik menggunakan $P C$ atau $H P$ yang harus terhubung dengan internet mengingat penyimpanan data tersebut secara online. Jika menggunakan $P C$, maka aplikasi ini diperuntukkan bagi Administartor untuk melakukan pengecekan secara online. Tetapi jika dijalankan dengan $H P$, maka aplikasi ini diperuntukkan bagi user yang bertugas secara mobile dalam pengambilan data. Harapannya, aplikasi ini diperuntukkan bagi controller dalam mengontrol user yang bersangkutan dalam melakukan proses pekerjaannya sehingga akan terjadi komunikasi secara 2 arah baik dari controller maupun user. Dalam pembuatan Sistem Patroli Security ini menjabarkan secara keseluruhan mengenai kebutuhan apa saja yang harus ada pada sistem, baik secara fungsional maupun non fungsional.

\subsection{Blok Diagram Sistem}

Blok diagram adalah diagram dari sebuah sistem, sistem terdahulu pada Perusahaan masih menggunakan sistem manual dengan alat yang dinamakan "Amano". Amano sendiri merupakan suatu alat yang cukup berukuran besar yang dilengkapi dengan kunci. Untuk cara kerja amano sendiri yaitu amano akan dibawa berkeliling untuk patroli dengan cara diselempangkan di bahu, kemudian amano akan mengambil data disetiap titiktitik patroli yang dimana pada setiap titik petugas security akan memasang kunci yang berbeda untuk mengambil datanya. Data yang diambil yaitu berupa data tempat area melakukan patroli. Setelah dilakukan pengecekan secara rinci mengenai patroli, petugas security disinyalir hanya melakukan patroli di beberapa titik saja dan di dalam sistem manual tersebut masih memungkinkan petugas security melakukan kecurangan pada saat melakakukan patroli. Proses kerja pada system ini di tunjukkan pada Gambar 1

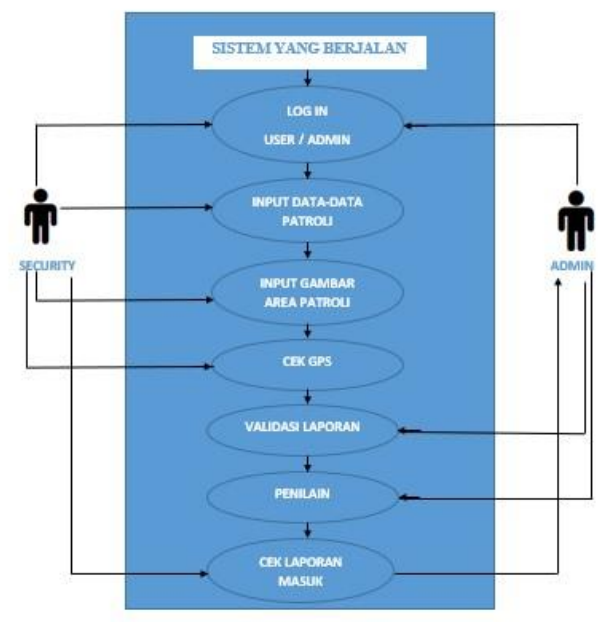

Gambar 1 Blok Diagram Sistem

\subsection{Flowchart Sistem}

Dalam penelitan dan pembuatan system patroli untuk security ini digambarkan dengan 2 flowchart untuk user/petugas security dan untuk admin/pengelola. 


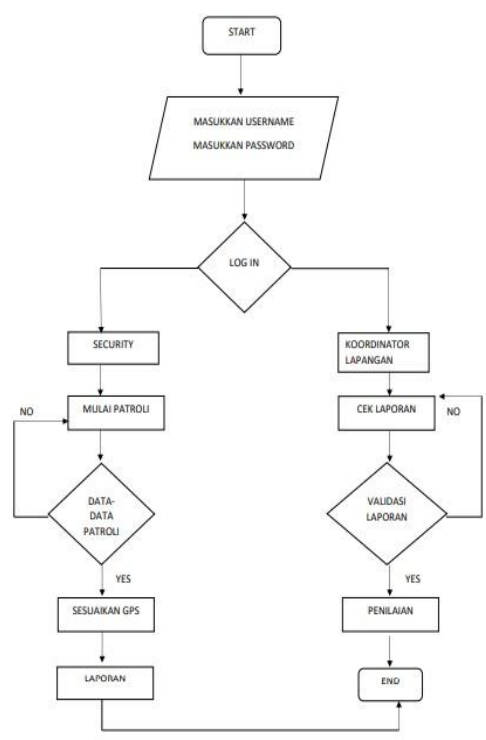

Gambar 2 Flowchart Sistem

Berdasarkan flowchart pada Gambar 2, user akan membuka dan masuk pada aplikasi dengan memasukkan Username dan Password masingmasing petugas security berbeda. Jika log in berhasil username dan password benar maka akan masuk pada cek data yang meliputi data valid dan laporan, Jika sesuai maka lanjut pada cek patroli yang meliputi input data, sesuaikan gps, dan mengirimkan laporan. Jika semua sudah valid maka proses selesai.

Sedangkan admin, akan membuka dan masuk pada aplikasi dengan memasukkan Username dan Password. Jika log in berhasil username dan password benar maka akan masuk pada cek laporan patroli yang dikirimkan oleh petugas security kemudian dicek oleh admin. Jika sesuai dan sudah valid maka lanjut pada penilaian. Jika semua sudah valid maka proses selesai.

\subsection{Perancangan Database}

\section{1) Tabel user}

Tabel tb_user merupakan tabel

yang digunakan untuk menyimpan data user.

Tabel 1 tb_user

\begin{tabular}{|c|c|c|}
\hline No & Name & Type \\
\hline 1 & nig & Int (15) \\
\hline 2 & username & $\operatorname{Varchar}(20)$ \\
\hline 3 & password & Varchar $(50)$ \\
\hline 4 & name & Varchar(50) \\
\hline 5 & nik & Char (12) \\
\hline 6 & jab & Varchar(30) \\
\hline 7 & pabrik & Varchar (20) \\
\hline 8 & $\log$ in_lv1 & Int(1) \\
\hline 9 & hp & Varchar(15) \\
\hline 10 & status & Int (1) \\
\hline 11 & pic & Varchar(15) \\
\hline
\end{tabular}

\section{2) Tabel Berita}

Tabel tb_berita merupakan tabel yang digunakan untuk memvalidasi data yang sudah dikirim oleh petugas security.

Tabel 2 tb_berita

\begin{tabular}{|c|c|c|}
\hline No & Name & Type \\
\hline 1 & Id berita & Int (5) \\
\hline 2 & dates & Date \\
\hline 3 & Jam & Time \\
\hline 4 & kategori & char(1) \\
\hline 5 & judul & varchar(100) \\
\hline 6 & isi & Text \\
\hline 7 & validasi & int(1) \\
\hline 8 & validby & $\operatorname{int}(2)$ \\
\hline 9 & dt_valid & Date \\
\hline 10 & nama_file & varchar(50) \\
\hline 11 & pengirim & varchar(15) \\
\hline 12 & lati & Double \\
\hline 13 & longi & Double \\
\hline 14 & dt record & datetime \\
\hline
\end{tabular}

\section{3) Tabel Jobs}

Tabel tb_jobs merupakan tabel yang digunakan untuk menyimpan data tugas yang diberikan untuk petugas security.

\begin{tabular}{|c|c|c|}
\hline \multicolumn{3}{|c|}{ Tabel 3 tb jobs } \\
\hline No & Name & Type \\
\hline 1 & id_jobs & int (11) \\
\hline 2 & tugas & text \\
\hline 3 & progres & int (2) \\
\hline 4 & status & int (11) \\
\hline 5 & deadline & date \\
\hline 6 & id_kar & int(2) \\
\hline 7 & valid & int(11) \\
\hline 8 & validby & $\operatorname{int}(11)$ \\
\hline 9 & dt_valid & datetime \\
\hline
\end{tabular}

\section{4) Tabel History}

Tabel tb_histori merupakan tabel yang digunakan untuk menyimpan data lama tugas yang diberikan untuk petugas security sekaligus pengecekan progres dari tugas yang diberikan

Tabel 4 tb_histori

\begin{tabular}{|c|c|c|}
\hline No & Name & Type \\
\hline 1 & id_his & int (3) \\
\hline 2 & Jobid & $\operatorname{int}(11)$ \\
\hline 3 & Tanggal & datetime \\
\hline 4 & Progress & int (11) \\
\hline 5 & Ket & text \\
\hline
\end{tabular}

\section{5) Tabel Kategory}

Tabel tb_kategori merupakan tabel yang digunakan untuk mengkategorikan laporan yang dikirimkan oleh petugas security pada saat laporan.

Tabel 5 tb_kategori

\begin{tabular}{|c|c|c|}
\hline No & Name & Type \\
\hline 1 & id kategori & int (3) \\
\hline 2 & Pic & varchar(20) \\
\hline 3 & Deskripsi & varchar $(200)$ \\
\hline 4 & Lat & double \\
\hline 5 & $\operatorname{lng}$ & double \\
\hline
\end{tabular}




\section{6) Tabel Nilai}

Tabel tb_nilai merupakan tabel yang digunakan penilaian terhadap kinerja petugas security.

Tabel 6 tb_nilai

\begin{tabular}{|c|l|l|}
\hline No & \multicolumn{1}{|c|}{ Name } & \multicolumn{1}{c|}{ Type } \\
\hline 1 & id_nilai & int (3) \\
\hline 2 & nik & Varchar(11) \\
\hline 3 & poin & int(11) \\
\hline 4 & ket & text \\
\hline
\end{tabular}

\section{IMPLEMENTASI DAN HASIL}

\subsection{Implementasi}

Implementasi

merupakan

penerapkan perancangan yang telah dilakukan terhadap sistem sehingga pengguna dapat memberi masukan demi berkembangnya sistem yang telah dibangun. Dalam tahap implementasi ini membuat beberapa tampilan untuk user dan untuk admin sebagai berikut:

\subsection{Menu Log in}

Pada Gambar 4 merupakan tampilan awal pada aplikasi mobile untuk system patroli security berbasis website. Pada halaman ini user akan melakukan log in terlebih dahulu. Jika user dan password benar maka akan langsung masuk di halaman selanjutnya, sebaliknya jika user dan password yang dimasukkan salah maka tidak dapat melakukan log in.

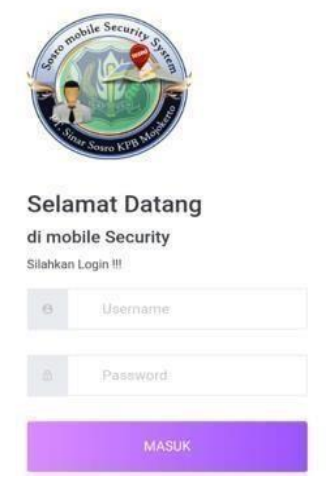

Gambar 3 Halaman Log in

\subsection{Tampilan Menu Dashboard}

Pada Gambar 4 merupakan tampilan setelah melakukan login jika telah berhasil melakukan log in dengan benar maka user akan langsung masuk pada halaman selanjutnya yaitu halaman dashboard.

Didalam halaman dashboard terdapat jumlah total patroli yang dilakukan, tugas yang belum finish, dan point user.

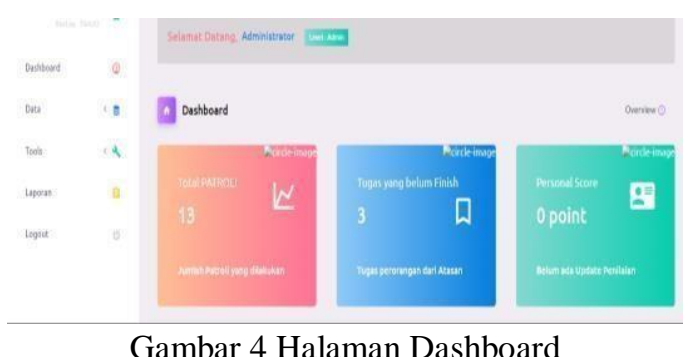

\subsection{Tampilan Menu Input Data}

Pada Gambar 5 merupakan tampilan input data merupakan tampilan yang akan diidikan oleh user atau petugas security untuk dikirimkan kepada admin bahwa petugas security tersebut sudah melakukan patroli sesuai dengan jadwalnya

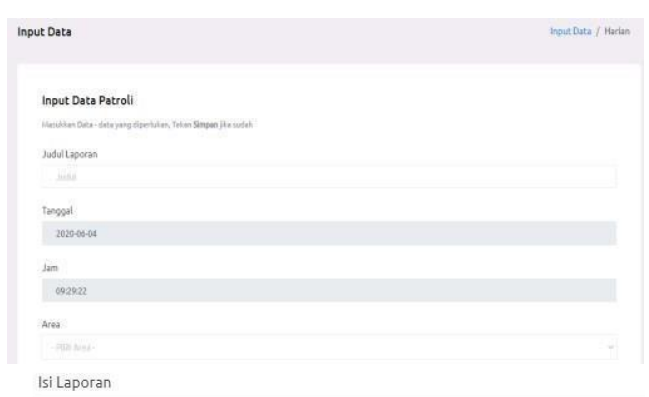

File upload
Choose File No file chosen

$\square$ Tanpa Foto

Gambar 5 Halaman input data patroli

\subsection{Tampilan Menu Cek GPS}

Pada Gambar 6 merupakan tampilan menu GPS merupakan tampilan pengecekan lokasi petugas security berada yang akan diminta mengirimkan pada saat melakukan patroli online.

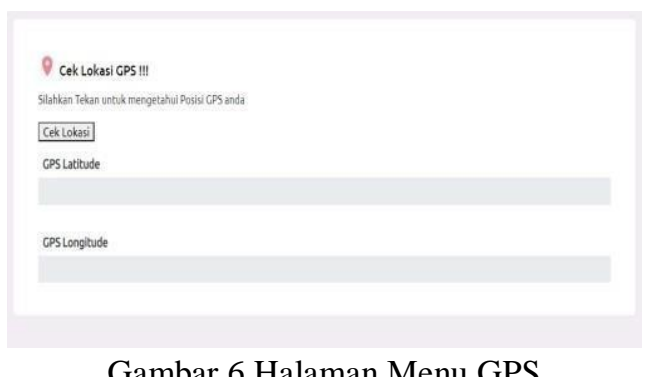

\subsection{Tampilan Update Laporan}

Pada Gambar 7 merupakan tampilan menu update laporan merupakan tampilan untuk mengontrol laporanlaporan terbaru yang dikirimkan oleh petugas security. 


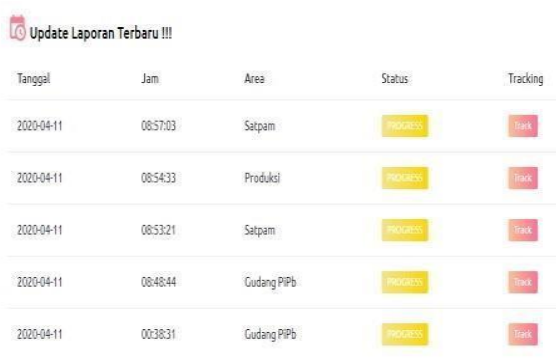

Gambar 7 Halaman Menu Update Laporan

\subsection{Tampilan Jobs}

Pada Gambar 8 merupakan tampilan menu jobs merupakan halaman yang dikelola oleh admin untuk memberikan tugas tambahan kepada petugas security.

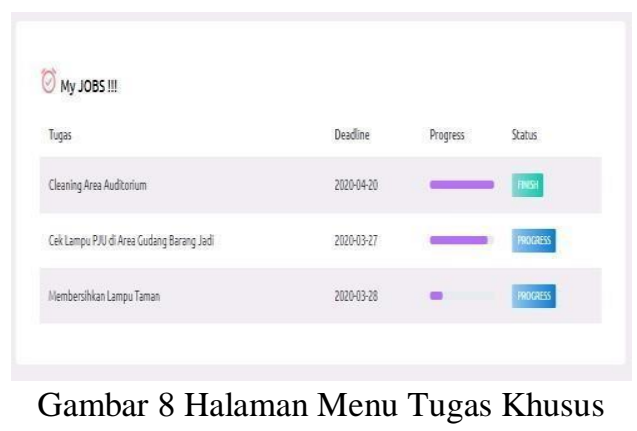

\subsection{Tampilan Menu Ganti Password}

Pada Gambar 9 merupakan tmpilan menu ganti password untuk user dan admin jika ingin mengganti password maka user dan admin akan dihubungkan pada menu halaman ganti password dan mengisikan password lama menjadi password baru .

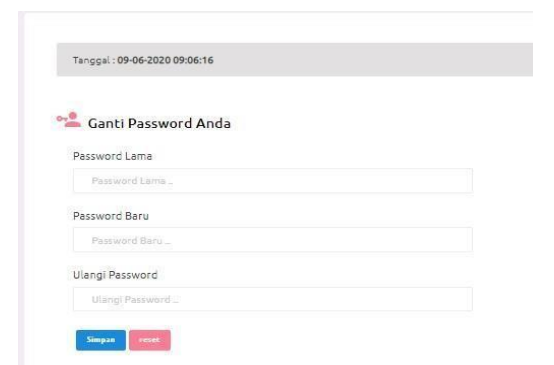

Gambar 9 Halaman Menu Ganti Password

\subsection{Tampilan Menu Scan}

Pada Gambar 10 merupakan tampilan berikut adalah tampilan untuk scan QR yang bisa diakses oleh user.

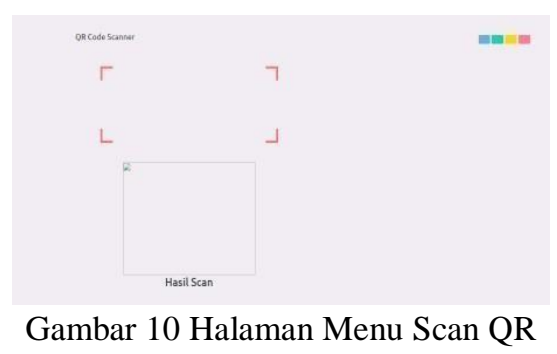

\subsection{Menu Log in Admin}

Pada Gambar 11 merupakan tampilan awal pada aplikasi mobile untuk system patroli security berbasis website. Pada halaman ini user akan melakukan log in terlebih dahulu. Jika user dan password benar maka akan lngsung masuk di halaman selanjutnya, sebaliknya jika user dan password yang dimasukkan salah maka tidak dapat melakukan log in.

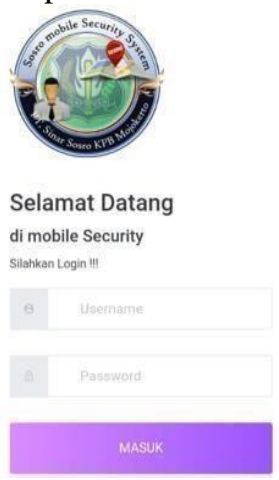

Gambar 11 Halaman Log in admin

\subsection{Menu Dashboard}

Pada Gambar 12 merupakan tampilan jika telah berhasil melakukan log in dengan benar maka user akan langsung masuk pada halaman selanjutnya yaitu halaman dashboard. Didalam halaman dashboard terdapat jumlah total patroli yang dilakukan, tugas yang belum khusus, dan point user.

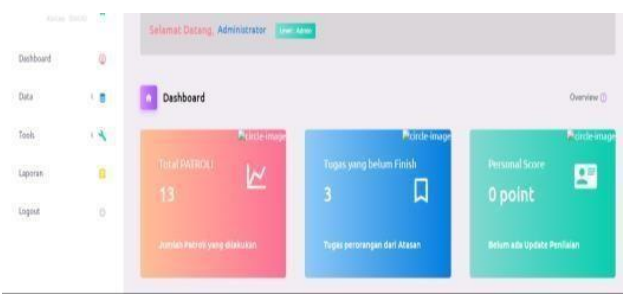

Gambar 12 Halaman Dashboard

\subsection{Menu Verifikasi Data}

Pada Gambar 13 merupakan tampilan ini merupakan tampilan yang dimilik oleh admin saja. Halaman ini berfungsi untuk memverifikasi data-data yang masuk yang sudah dikirimkan oleh user kepada admin untuk mengecek apakah user sudah bekerja.

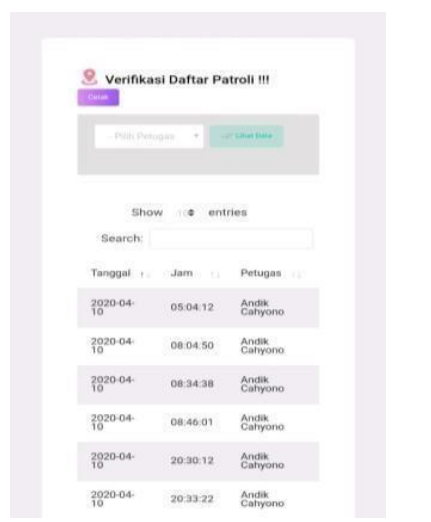

Gambar 4.13 Halaman Verifikasi Data 


\subsection{Menu Ganti Password}

Pada Gambar 14 merupakan tampilan menu ganti password untuk user dan admin jika ingin mengganti password maka user dan admin akan dihubungkan pada menu halaman ganti password dan mengisikan password lama menjadi password baru .

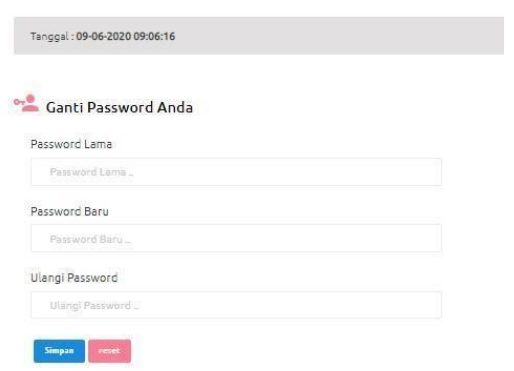

Gambar 14 Halaman Menu Ganti Password

\subsection{Tampilan Menu Daftar Patroli}

Pada Gambar 15 merupakan tampilan menu daftar patroli merupakan tampilan yang akan memunculkan semua laporan-laporan yang sudah dikirimkan oleh petugas security sesuai dengan jadwal masing-masing petugas security.

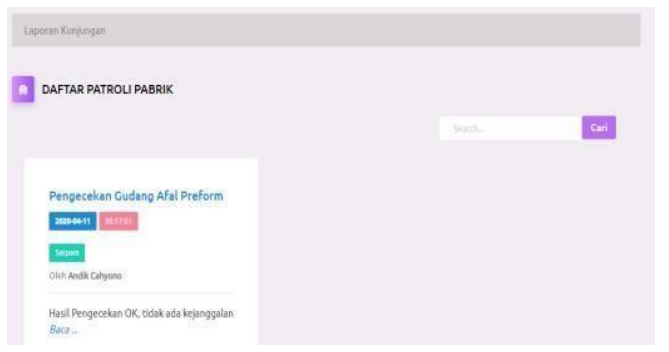

Gambar 15 Halaman Daftar patroli

\section{KESIMPULAN DAN SARAN}

\subsection{Kesimpulan}

Berdasarkan hasil dari pembuatan aplikasi untuk system patroli security, maka dapat diambil kesimpulan sebagai berikut :

1. Pada pengujian fungsional pada minimal Android 4.0, fungsi $100 \%$ sudah sesuai kebutuhan yang diinginkan.

2. Pada pengujian user yang telah dilakukan kepada 10 petugas security dan 1 petugas admin menyatakan bahwa $100 \%$ system dapat membantu mempermudah dalam mengawasi area yang ada di perusahaan.

3. Pada pengujian aplikasi sangat mudah untuk bisa berjalan dan di operasikan guna membantu petugas security dalam melakukan patroli.

\subsection{Saran}

Agar dalam aplikasi ini berjalan dengan baik kedepannya, maka ada beberapa hal yang perlu dilakukan yaitu sebagai berikut :

1. Penulis berharap aplikasi nantinya dapat dijalankan tidak hanya di Android saja, melainkan Windows phone, dll.

2. Menerapkan metode perhitungan jarak pada system agar system berjalan lebih efisien dan efektif.

3. Menambahkan pemberitahuan kepada koordinator lapangan untuk keadaan yang sangat darurat.

\section{DAFTAR PUSTAKA}

[1] Arief Rahman . (2018). "PERANCANGAN APLIKASI PATROLI KEAMANAN DAN KESELAMATAN KAMPUS", (15), 1

[2] H. Burhanuddin, S. M. (2017). STIA Setih Setio Muara Bungo. EFEKTIFITAS PELAKSANAAN PATROLI TERPADU DALAM UPAYA MENEKAN TINGKAT KRIMINALITAS, 11(10), 13.

[3] Pengertian dan funsi HTML. (2010, Januari 1). (NAWADWIPA) Retrieved 8 Juni, 2020, from https://www.nawadwipa.co.id/pengertiandanfungsi-html-hypertext-markup-language/

[4] Rahman. (2008). PERANCANGAN APLIKASI PATROLI KEAMANAN DAN. PERANCANGAN APLIKASI PATROLI KEAMANAN DAN, 6.

[5] SALAMADIAN. (2006, April 4). (SALAMADIAN) Retrieved Mei 3, 2020, from https://salamadian.com/pengertian-data/

[6] Setiawan, F. (2017). Jurnal Monitoring. APLIKASI MONITORING KEHADIRAN SISWA SMKN 1 BANDUNG BERBASIS ANDROID , 1(12), 8. "PHP Syntax," w3schol, 3 Agustus 2009. [Online]. Available: https://www.w3schools.com/php/php_syntax.as p. [Diakses 1 Juni 2020].

[7] "MySQL," MySQL, 4 Februari 2015. [Online]. Available: https://www.mysql.com/. [Diakses 1 Juni 2020].

[8] Sevima. (2015). Hosting MySQL. Hosting, 7. Teguh Affrianto. (2015). Pengertian Android dan Smartphone . Kelebihan smartphone. Smartphone, 5.

[9] Peter Salim. (2002) . Keamanan Security. Patroli Security. 9 